\title{
Tuning size and catalytic activity of nano-clusters of cobalt oxide
}

\author{
R VENKAT NARAYAN, ${ }^{+}$VINOD KANNIAH ${ }^{+}$and ARUNA DHATHATHREYAN* \\ Chemical Laboratory, Central Leather Research Institute, Adyar, Chennai 600020 \\ ${ }^{+}$Present address: Sathya Bama Deemed University, Jeppiar Nagar, Old Mahabalipuram Road, Chennai 600119 \\ e-mail: adhatha@md5.vsnl.net.in
}

MS received 15 June 2005; revised 6 August 2005

\begin{abstract}
Cobalt oxides were prepared by three different methods: (1) by reacting cobalt nitrate with oxalic acid, (2) co-precipitating cobalt nitrate with sodium carbonate, and (3) using sodium dodecyl sulphate as organic surfactant. All three samples were characterized before and after calcination by solvent extraction and the resulting products examined by IR spectroscopy. In the case of method 3, the removal of surfactant was followed by TGA studies. Products from all three methods were identified by XRD. Peaks in low angle XRD indicate the porous nature of the oxides. The morphology of the pores was studied by transmission electron microscopy. Some irregular pore structures were obtained for samples from methods 1 and 2, with an average size of 4-6 nm. Only the product from method 3 using SDS as template showed ordered structure and optimum size, and Brunauer-Emmet-Teller surface areas of the as-prepared, as well as the treated samples, exhibited H3 type hysteresis. The samples from the three methods were used as catalysts in the oxidation reaction of cyclohexane under mild conditions and the catalytic efficiency of the cobalt oxide was comparable with mesoporous cobalt oxides.
\end{abstract}

Keywords. Cobalt oxide; nano cluster; catalytic activity; pore sizes.

\section{Introduction}

It is well known that supported catalysts containing cobalt in the metallic, oxidic, or sulphided state are very important in heterogeneous catalysis. ${ }^{1-13}$ Cobalt and nickel oxides are important materials that find applications in different fields such as catalysis, various types of sensors, electrochromic, electrical and other opto-electronic devices. Humidity-sensitive $\mathrm{Co}_{3} \mathrm{O}_{4}$ active in the visible wavelength region at room temperature has been reported. ${ }^{14}$ Recently, there was an excellent review ${ }^{15}$ on the adsorption and applications of cobalt species on the interface, between aqueous solutions and metal oxides. Due to various oxidation states of these oxides, they find special application as electrochromic materials exhibiting anodic electrochromism, changing colour from grey to pale yellow. ${ }^{16}$ Nickel and cobalt oxides also have applications as electrochemical capacitors and in coloured glasses. ${ }^{17}$ Cobalt-based catalysts are of interest in the field of heterogeneous catalysis and have been used in hydrosulphurization and in hy-

*For correspondence drogenation. ${ }^{18,19}$ Khodakov et al reported on the preparation and localization of cobalt and catalytic behaviour of Co-containing MCM-41 and SBA-15 materials in Fischer-Tropsch synthesis. ${ }^{20}$ In this regard, mesoporous materials obtained by a supramolecular templating mechanism have found wide applications in recent times due to their high surface area, narrow pore size distribution, large pore volume and hydrothermal stability. ${ }^{21}$ Several mechanisms such as liquid crystal templating, ${ }^{22,23}$ cooperative templating and ligand-assisted templating ${ }^{23}$ have been used to design mesophasic structures as part of the templating mechanisms.

A number of papers have appeared in the literature on the synthesis and structures of metal oxides ${ }^{24,26}$ including laser ablation of cobalt and cobalt oxides $\left(\mathrm{CoO}\right.$ and $\left.\mathrm{Co}_{3} \mathrm{O}_{4}\right)$ to prepare their nanoparticles. ${ }^{19} \mathrm{In}$ this paper, nanocrystalline cobalt oxide was prepared through three routes namely, precipitation method (method I), sol/gel method (method II) and templating method (method III) and the efficacy of the catalyst obtained by each of the three methods was tested on a specific reaction. The final pore size distribution, surface area and local ordering if any was related to the catalytic activity. 


\section{Experimental}

All the reagents used in this study were AR Grade and obtained from Merck, India. The surfactant sodium dodecyl sulphate (SDS) used in the present work was from Sigma Chemicals, USA and was 99.9\% pure. Deionized water from a Milli-Q (Millipore) system was used for the experiments and the preparation of cobalt oxide was carried out using methods I, II and III.

\subsection{Synthesis}

In method I cobalt nitrate and oxalic acid were taken in mol. ratio $0 \cdot 2: 1$ in $25 \mathrm{ml}$ ethanol. The mixture was stirred for $5 \mathrm{~h}$ at room temperature $(T=295 \mathrm{~K})$. The precipitate that appeared after this time was pink in colour and was extensively washed with ethanol to remove any unreacted starting compounds. The precipitate was dried at $353 \mathrm{~K}$ and the resulting solid was then calcined at 673,773 and $873 \mathrm{~K}$ to get the required cobalt oxide.

The reaction proceeds as shown below,

$$
\begin{aligned}
& \mathrm{Co}\left(\mathrm{NO}_{3}\right)_{2}+(\mathrm{COOH})_{2} \rightarrow \mathrm{Co}(\mathrm{OH})_{2}+2 \mathrm{CO}_{2}+2 \mathrm{NO}_{2}, \\
& 3 \mathrm{Co}(\mathrm{OH})_{2}+\mathrm{NO}_{2} \rightarrow \mathrm{Co}_{3} \mathrm{O}_{4}+3 \mathrm{H}_{2} \mathrm{O}+\mathrm{NO}
\end{aligned}
$$

In method II, cobalt nitrate was co-precipitated with $4 \mathrm{~N} \mathrm{Na}_{2} \mathrm{CO}_{3}$ in a magnetic stirrer for $5 \mathrm{~h}$ at room temperature. The gel formed was washed repeatedly with deionised distilled water till the filtrate was devoid of any impurities. The remaining solid was dried in air at $353 \mathrm{~K}$ and calcined at 673,773 and $873 \mathrm{~K}$ for an hour each to get the required oxide.

The reaction proceeds as follows,

$$
\begin{aligned}
& \mathrm{Co}\left(\mathrm{NO}_{3}\right)_{2}+\mathrm{Na}_{2} \mathrm{CO}_{3} \rightarrow \mathrm{CoCO}_{3}+2 \mathrm{NaNO}_{3}, \\
& \mathrm{CoCO}_{3} \stackrel{\Delta}{\longrightarrow} \Delta \mathrm{CoO}+\mathrm{CO}_{2}, \\
& \mathrm{CoO} \rightarrow \text { (in air and heating) } \mathrm{Co}_{3} \mathrm{O}_{4} .
\end{aligned}
$$

In method III, cobalt nitrate, sodium dodecyl sulphate (SDS), urea and deionised water were taken in a mol. ratio of $1: 2: 30: 60$. The mixture was stirred at $313 \mathrm{~K}$ for $1 \mathrm{~h}$ at room temperature to yield a transparent solution. The contents were then heated to and maintained at $353 \mathrm{~K}$ for $1 \mathrm{~h}$. The resulting mixture was cooled to room temperature to prevent further hydrolysis of urea. The solid was then washed a few times with water and then dried in air for $1 \mathrm{~h}$ at $313 \mathrm{~K}$. The final solid was extensively washed with ethanol and then dried in air. The sample was then calcined at 673,773 and $873 \mathrm{~K}$ for $4 \mathrm{~h}$. The reaction can be represented as,

$$
\begin{aligned}
\mathrm{Co}\left(\mathrm{NO}_{3}\right)_{2}+2 \mathrm{C}_{12} \mathrm{H}_{25} \mathrm{OSO}_{3} \mathrm{Na} \rightarrow \mathrm{Co}(\mathrm{OH})_{2} & \\
+ & 2 \mathrm{C}_{12} \mathrm{H}_{25} \mathrm{OSO} \mathrm{OS}_{3} \mathrm{H}+2 \mathrm{NaNO}_{3}, \\
\left(\mathrm{H}_{2} \mathrm{O} / \text { urea }\right) &
\end{aligned}
$$$$
\mathrm{Co}(\mathrm{OH})_{2} \stackrel{\Delta}{\longrightarrow} \mathrm{Co}_{3} \mathrm{O}_{4} \text {. }
$$

\subsection{Characterization}

The thermal decomposition behaviour of the samples was studied by thermogravimetric analysis (TGA), and differential thermal analysis (DTA) on a Mettler TGA/SDTA 851. X-ray diffraction (XRD) patterns were recorded using a Bruker D8 diffractometer using $\mathrm{Co}-\mathrm{K} \alpha$ radiation with $2 \theta$ ranges from $10^{\circ}$ to $80^{\circ} \mathrm{C}$. A transmission electron nicroscope (TEM) was used to study particle sizes and shapes. The powder was dispersed in ethanol and the TEM micrographs were employed using a Philips STEM microscope. FTIR spectra were determined on a Perkin-Elmer RX-1 model IR spectrophotometer in $\mathrm{KBr}$ medium. The surface area measurements were performed by a Micrometric (Gemini 2375) surface area analysers. The nitrogen adsorption and desorption isotherms were measured at $77 \mathrm{~K}$ temperature after heating the sample at $100^{\circ} \mathrm{C}(373 \mathrm{~K})$ for $2 \mathrm{~h}$.

\subsection{Catalytic activity}

Catalytic activities of the samples from the above procedures were tested for the oxidation of cyclohexane. Cyclohexane was distilled over $\mathrm{CaH}_{2}$ prior to use. The reaction was carried out in a glass reactor maintained at $70^{\circ} \mathrm{C}$, where $2 \mathrm{ml}(18.5 \mathrm{mmol})$ of cyclohexane, $2.5 \mathrm{ml}(27.5 \mathrm{mmol})$ of isobutyraldehyde (mol. ratio $1.5: 1$ ), a catalytic amount of acetic acid $0.06 \mathrm{ml}(1 \mathrm{mmol})$ and $0.05 \mathrm{~g}$ of catalyst sample prepared from the present study (from any one of the 3 procedures mentioned here) were taken. The reaction mixture was kept under 1 atm of oxygen and continuously stirred by a magnetic stirrer for 15$17 \mathrm{~h}$. The starting alkane was used as an internal standard in the final chromatographic analysis. The conversion was defined as a percentage of the starting alkane converted into product. 
The conversion of cyclohexane into cyclohexanol and cyclohexanone was checked by gas chromatography using a Varian-400, equipped with a packed column (10\% carbo wax 400 on chromosorb 101).

\section{Results and discussions}

Samples of cobalt oxide obtained from the three procedures were characterized by XRD. The XRD of the sample from method 1 shows the amorphous nature of the material (figure 1a). The XRD pattern of the sample from method 2 showed the presence of two oxides (i.e. $\mathrm{CoO}$ and $\mathrm{Co}_{3} \mathrm{O}_{4}$ ) (figure $1 \mathrm{~b}$ ), while its the calcined sample (at $773 \mathrm{~K}$ ) showed the presence of only one phase, $\mathrm{Co}_{3} \mathrm{O}_{4}$ (figure 1c). Figures $1 \mathrm{~d}$ and e show the XRD patterns of samples from procedure 3 before and after calcinations at $773 \mathrm{~K}$. The peak widths of the sample heated at $773 \mathrm{~K}$ are narrower than for all other samples indicating the greater crystalline nature of the sample.

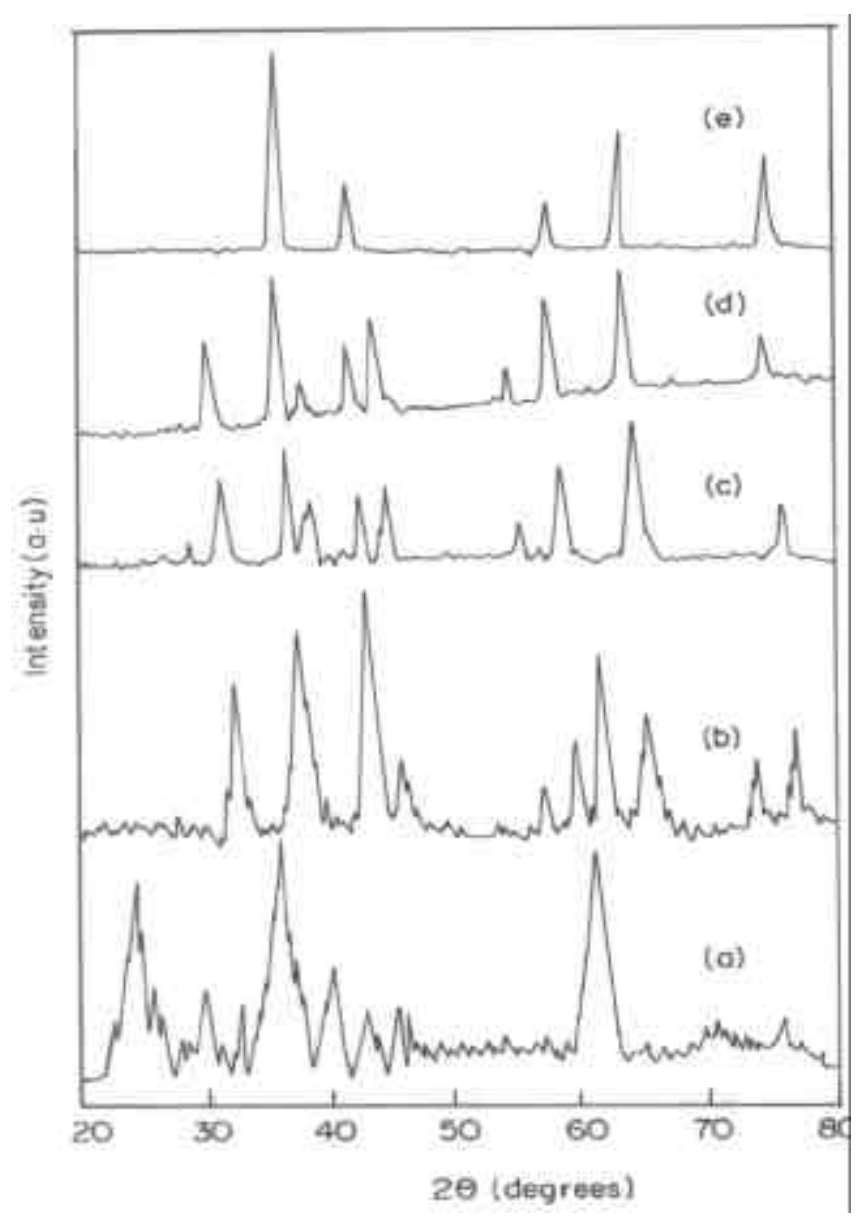

Figure 1. XRD of sample 1 (a); sample 2 (b) before and (c) after calcinations; sample 3 (d) before and (e) after calcinations.
The low angle XRD pattern of sample 3 (after calcination) is given in figure 2 . The peak at $2 \vartheta$ at 1.60 for the sample corresponds to $\mathrm{Co}_{3} \mathrm{O}_{4}$. The corresponding value for $d$ is $5.67 \mathrm{~nm}$. This value agrees with the pore sizes obtained from sorption experiments. The wide band seen in the XRD pattern may be due to the large distribution of pore distances leading to long range ordering in the oxide sample formed.

Since procedure I gave samples which appear amorphous, have quite low surface area and show some presence of hydroxides even after calcination. most of the studies were carried on samples obtained from Procedures II and III (here after called samples 2 and 3 respectively). FTIR spectra of samples 2 and 3 , and of them after calcination are shown here in figure $3 \mathrm{a}-\mathrm{d}$.

Two sharp peaks at 2911 and $2848 \mathrm{~cm}^{-1}$ in the case of sample 3 are assigned to the $\mathrm{C}-\mathrm{H}$ sym and asym vibration of $-\mathrm{CH}_{2}-$ in SDS. These peaks disappeared after calcination, and this confirms that calcinations is the only effective method for the removal of surfactant in the samples. This observation also explains the low surface area of the sample 3 . The broad hump at $3463 \mathrm{~cm}^{-1}$ in sample 2 is attributed to adsorbed water (figure $3 \mathrm{a}$ ). The peak is not observed after calcination or solvent extraction. The peaks centred at 1558 and $1383 \mathrm{~cm}^{-1}$ are assigned to residual acetate

The peaks at 624 and $531 \mathrm{~cm}^{-1}$ are characteristic of the metal oxide bands. On calcinations the bands shift to higher wave numbers. This blue shift indicates the formation of cobalt oxide of a higher bond order. In fact, the peaks at $\left(675,571\right.$ and $425 \mathrm{~cm}^{-1}$ are assigned to the dominance of $\mathrm{Co}_{3} \mathrm{O}_{4}$.

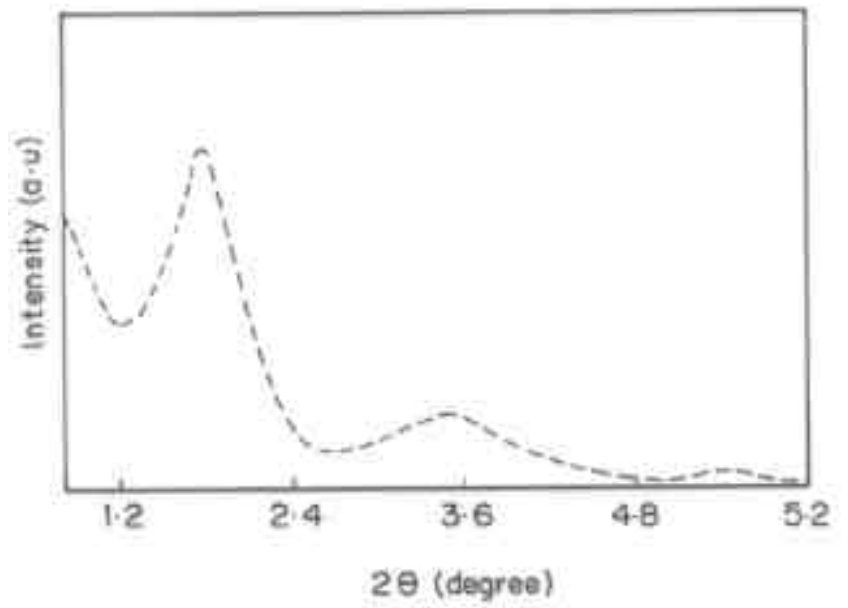

Figure 2. Low angle XRD of sample 3 (after calcination). 
Thermogravimetric plots for samples 2 and $3 \mathrm{Co}$ as-prepared samples are given in figures $4 \mathrm{a}$ and $\mathrm{b}$. The initial weight loss of about $10 \%$ at temperature up to $110^{\circ} \mathrm{C}$ is attributed to the loss of water and any adsorbed species. Both samples show almost a plateau at higher temperature till $275^{\circ} \mathrm{C}$. Further weight loss of about $20 \%$ between the temperatures ranges of $275-325^{\circ} \mathrm{C}$ is attributed to slight loss of the porelike structures. The slow but continuous loss in weight up to $500^{\circ} \mathrm{C}$ is attributed to the loss of organic materials. Further, a very slow but constant decrease in the weight up to $750^{\circ} \mathrm{C}$ has been observed in both the cases.

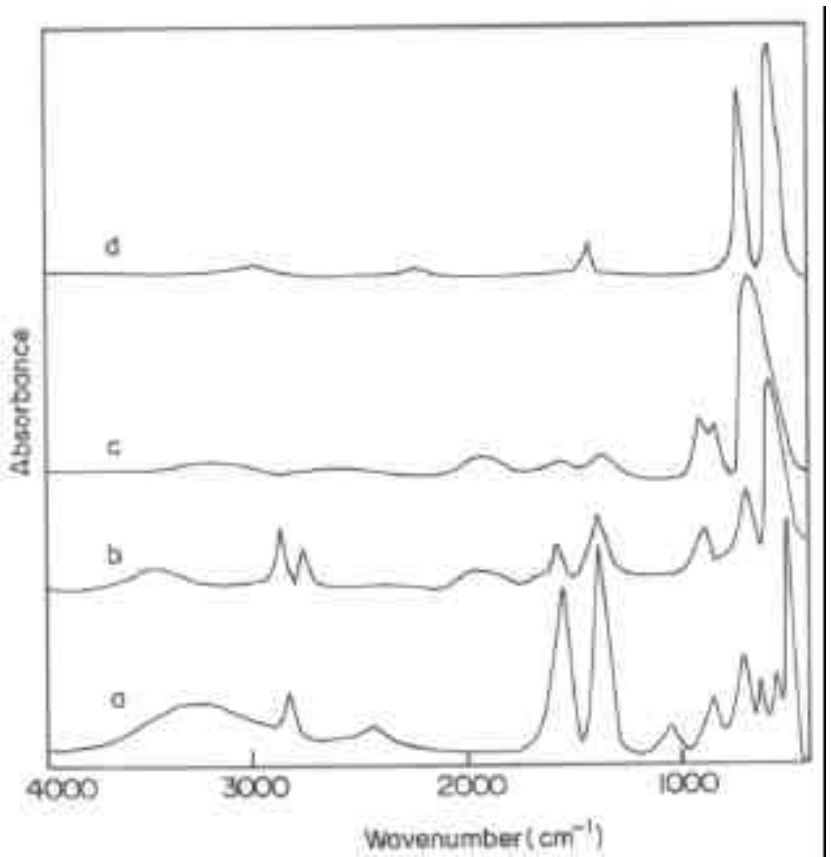

Figure 3. FTIR spectra of (a) sample 2 and (b) sample 3 before calcinations; (c) sample 2 and (d) sample 3 after calcinations.

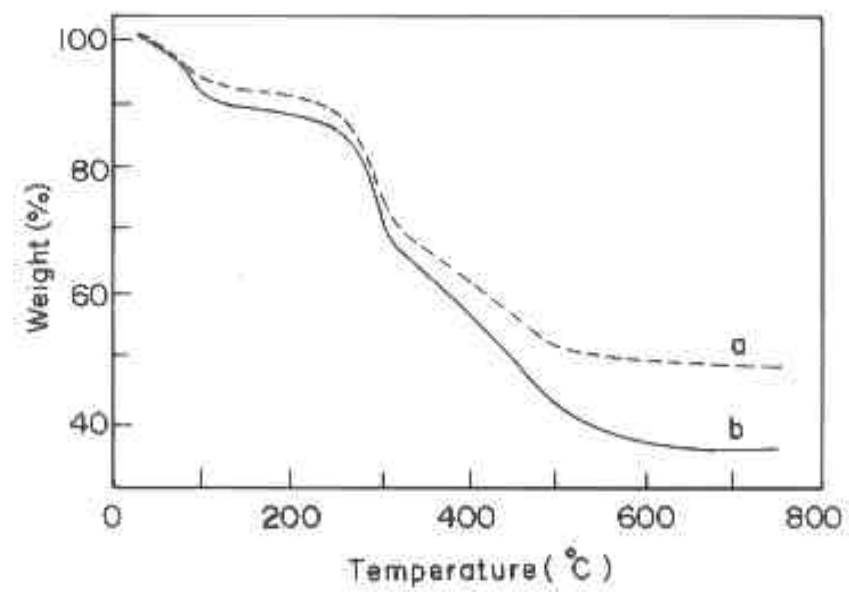

Figure 4. Thermogravimetric plots of samples 2 and 3 .
TEM photographs of the samples before and after calcination are given in figure 5 (samples $1-3$ in figures $5 \mathrm{a}-\mathrm{c}$ respectively). No open pore structures can be seen in the TEM photograph of the sample 1 . The organic trashes are more prominent objects in these photographs, whereas in sample 2 the beginning of some irregular pore structure can be seen (figure $5 b$ ). Since the sample is oven-dried after repeated washing, any packing order seen could be only due to the geometrically well-defined channels of the oxide formed and such structures should be fairly stable even on heating.

Average sizes of the particles are a few tens of nanometres, while pores with average diameter of 2-7 nm can be seen in sample 3 (figure $5 \mathrm{c}$ ). A complete lack of uniformity in the shapes and sizes of the
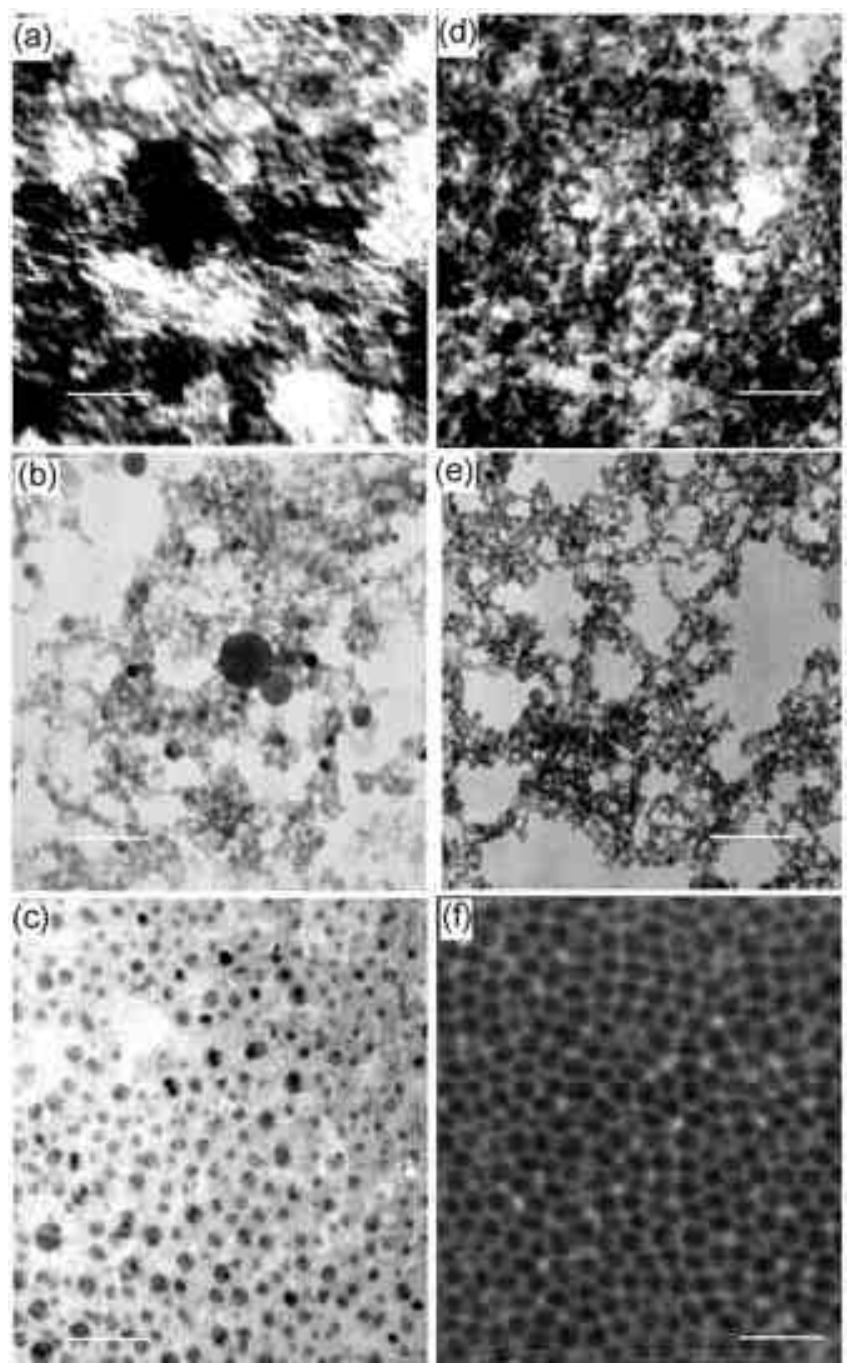

Figure 5. TEM photographs of samples 1, 2 and 3 (a)(c) before calcination and (d)-(f) after calcination (scale bar $=20 \mathrm{~nm}$ ). 
Table 1. BET surface area measurement data.

\begin{tabular}{lcc}
\hline Sample & Surface area $\left(\mathrm{m}^{2} / \mathrm{g}\right)$ & $\begin{array}{c}\text { Pore volume } \\
(\mathrm{cc} / \mathrm{g}) \text { at } 0.99 P / P_{0}\end{array}$ \\
\hline Sample 1 & Well below instrument limit & 0.42 \\
Sample 1, calcined at 773 K & $20 \cdot 32$ & 0.14 \\
Sample 2 & 40.43 & 0.35 \\
Sample 2, calcined at 773 K & 56.55 & $0 \cdot 12$ \\
Sample 3 & $60 \cdot 42$ & 0.64 \\
Sample 3, calcined at 773 K & 107.44 & 0.32 \\
\hline
\end{tabular}

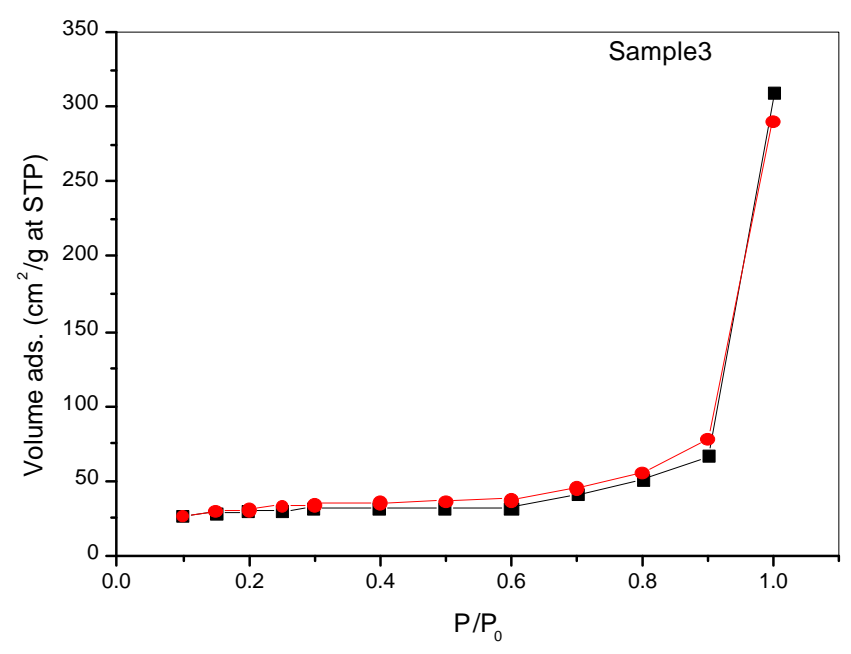

Figure 6. Adsorption-desorption isotherm for sample 3.

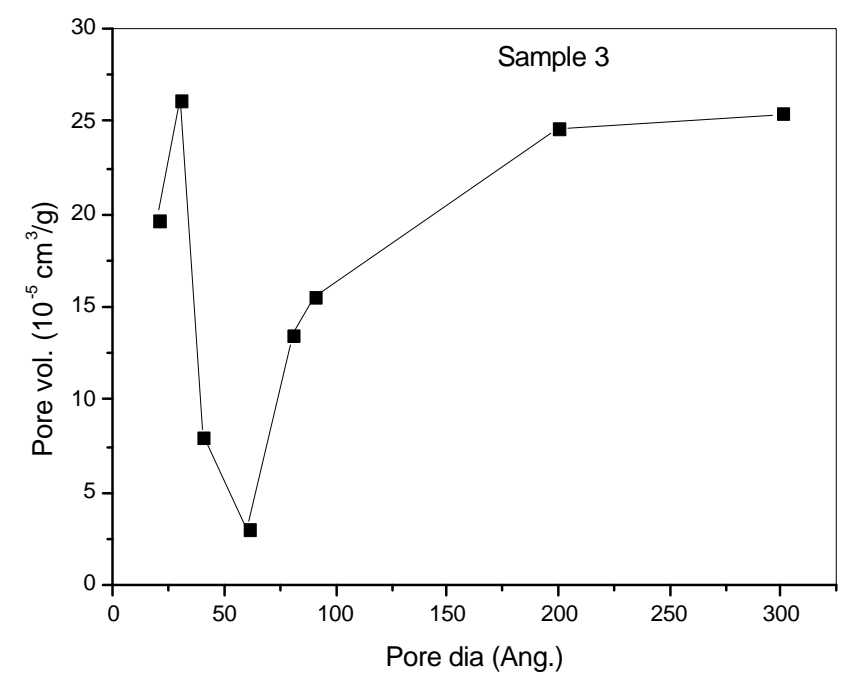

Figure 7. Pore size distribution of sample 3.

pores has been observed. While calcination of samples 1 and 2 leads to collapse of the porous structures, in sample 3 the pore structure is retained.

BET surface area measurements show a total surface area of $40-60 \mathrm{~m}^{2} / \mathrm{g}$ for samples 2 and 3 before calcination whereas for sample 1 it is below the measurable limit of the instrument. These data are given in table 1. An increase in the surface area of sample 2 compared to sample 1 is observed which goes up to $56.55 \mathrm{~m}^{2} / \mathrm{g}$, while for sample 3 , the measured area is $60 \mathrm{~m}^{2} / \mathrm{g}$. The surface areas of all three samples increase on calcination. The surface area after calcination at $573 \mathrm{~K}$ is about $20 \mathrm{~m}^{2} / \mathrm{g}$ for sample 1 , $56 \mathrm{~m}^{2} / \mathrm{g}$ for sample 2 and $107 \mathrm{~m}^{2} / \mathrm{g}$ for sample 3 . Finally, after calcination at $873 \mathrm{~K}$ all the mesostructures are damaged and the surface area falls below $10 \mathrm{~m}^{2} / \mathrm{g}$. The adsorption-desorption isotherm for sample 3, having the best surface area, is given in figure 6 .

The adsorption-desorption curve shows an $\mathrm{H} 3$ type of hysteresis (according to IUPAC classification). ${ }^{27}$ Many factors are thought to influence adsorption hysteresis, and specific pore structures have often been identified with the shape of hysteresis loops. Thus H3, which does not exhibit any limiting adsorption at high $P=P_{0}$, is often associated with aggregates (i.e., an assembly of particles, which are loosely coherent) having slit-shaped pores. Figure 7 presents the pore size distribution for the same sample, obtained according to the Barrett-Joyner-Halenda (BJH) method, using the Halsey equation for multilayer thickness. ${ }^{28}$ This plot shows that the majority of peaks correspond to the $2 \mathrm{~nm}$ range.

\subsection{Catalytic activity}

Cobalt oxide samples obtained by the three procedures have been used as catalysts in the oxidation of cyclohexane. Performances of various cobalt-based catalysts from our data archives, ${ }^{27,28}$ as well as that the current catalysts, are shown in table 2 .

The data shown in table 2 demonstrate that catalytic properties depend on a number of factors such as the particle size and surface area, as well the structure of the catalyst. Maximum conversion of cyclohexane has been observed when amorphous Co was used as a catalyst at $40 \mathrm{~atm}$ of $\mathrm{O}_{2}$ (at room temperature). ${ }^{27,28}$

The conversion of cyclohexane on the current porous cobalt catalyst is comparable with the result ob- 
Table 2. Performance of catalysts from different methods in the oxidation of a hydrocarbon.

\begin{tabular}{lcccc}
\hline Catalyst & Particle size $(\mathrm{nm})$ & Temp. $\left({ }^{\circ} \mathrm{C}\right)$ & Pressure $($ atm $)$ & Conversion $(\%)$ \\
\hline Sample 1 & $5-10$ & 70 & 1 & $1 \cdot 1$ \\
Sample 2 & $10-20$ & 70 & 1 & $4 \cdot 5$ \\
Sample 3 & $80-150$ & 70 & 1 & $9 \cdot 7$ \\
$\mathrm{Co} \mathrm{powder}^{27,28}$ & 10 & 70 & 1 & $10 \cdot 0$ \\
$\mathrm{Co}_{3} \mathrm{O}_{4}{ }^{27,28}$ & 20 & 70 & 1 & $4 \cdot 6$ \\
$\mathrm{Fe}^{-C o} / \mathrm{TiO}_{2}{ }^{27,28}$ & 30 & 70 & 1 & $12 \cdot 5$ \\
msp-Co oxides $^{27,28}$ & $100-200$ & 70 & 1 & $10 \cdot 0$ \\
\hline
\end{tabular}

msp: mesoporous

tained on the supported $\mathrm{Fe}-\mathrm{Co} / \mathrm{Fe}$ catalyst and is nearly of the same order as that reported earlier on nano-structured cobalt oxide with regular pore structure. ${ }^{29}$ This demonstrates the advantages of a Co oxide catalyst of high surface area in this reaction. The selectivity of conversion of cyclohexanol to cyclohexanone was found to be similar to previously reported data. ${ }^{28}$ From this study, it is clear that the current catalysts do not provide activities as good as that of Co catalyst at high oxygen pressure (which is not expected). However, their activity is better than or as good as that of catalysts from previous reports. The reaction mechanism for this type of conversion has been discussed earlier, ${ }^{27,28}$ and the same mechanism may be applicable in this present study also.

In conclusion, the structure of cobalt oxides from different procedures differ in pore sizes and surface areas as well as in their catalytic activities. While the precipitation technique is less cumbersome in terms of preparation, the resulting cobalt oxide is low in surface area and some percentage of hydroxide is always present leading to low catalytic activity.

Samples 2 and 3 have comparable pore size distributions. However, sample 3 is organized better due to the templating mechanism, leading to more order, larger surface area and thus to maximum catalytic activity.

\section{References}

1. Liotta L F, Pantaleo G, Macaluso A, Di Carlo G and Deganello G 2003 Appl. Catal. A245 167

2. Horiuchi T, Fujiwara T, Chen L, Suzuki K and Mori T 2002 Catal. Lett. 78319

3. Nanba T, Uemura A, Ueno A, Haneda M, Hamada H and Kakuta N 1998 Bull. Chem. Soc. Jpn. 712331

4. Torncrona A, Skoglundh M, Thormahlen P, Fridell E and Jobson E 1997 Appl. Catal. B14 131

5. Thomson J 1996 Catal. Lett. 40119

6. Okamoto Y, Adachi T, Nagata K, Odawara M and Imanaka T 1991 Appl. Catal. 73249

7. El-Shobaky G A, Fagal G A and Saber T M H 1987 Bull. Soc. Chim. Fr. 547
8. Hernadi K, Fonseca A, Piedigrosso P, Delvaux M, Nagy J B and Bernaerts D 1997 Catal. Lett. 48229

9. Bailie J E, Rochester C H and Hutchings G J 1997 J. Chem. Soc., Faraday Trans. 934389

10. Lapidus A, Krylova A, Rathousky J, Zukal A and Jancalkova M 1992 Appl. Catal. A80 1

11. Ho S W, Houalla M and Hercules D M 1990 J. Phys. Chem. 946396

12. Nitta Y, Ueno K and Imanaka T 1989 Appl. Catal. 569

13. Lycourghiotis A, Kordulis Ch and Bourikas K 2002 In Encyclopedia of surface and colloid science (ed.) A Hubbard (New York: Marcel Dekker) p. 1366

14. Fischer Rivera E, Atakan B and Kohse-Hoinghaus K 2001 J. Phys. IV 113

15. Bourikas K, Kordulis C, Vakros J and Lycourghiotis A 2004 Adv. Colloid Interface Sci 11097

16. Granquist C G 1995 Handbook of inorganic electrochromic materials (Amsterdam: Elsevier)

17. Fujii E 1996 Eur. Patent No. EP0733 721A1

18. The encyclopedia of catalysis 2004 (New York: John Wiley \& Sons)

19. Tsujia T, Hamagamia T, Kawamurab T, Yamakia J and Masaharu T 2005 Appl. Surf. Sci. 243214

20. Khodakov A Y, Zholobenko V L, Bechara R. and Durand D 2005 Microporous Mesoporous Mater. 7929

21. Beck J S, Vartuli J C, Roth W J, Lenowicz M E, Kresge C T Schmitt K D, Chu C T W, Olson D H, Shepard E W, McCullen S B, Higgins J B and Schlenker J L 1992 J. Am. Chem. Soc. 11410834

22. Huo Q, Margolese D I and Stucky G D 1995 Science 267865

23. Antonelli D M and Ying J Y 1995 Angew. Chem., Intl. Ed. Engl. 342014

24. Wirnsberger G, Gatterrer K, Fritzer H P, Grogger W, Pillep B, Behrens P, Hansen M F and Bender Koch C 2001 Chem. Mater. 131463

25. Banerjee S, Santhanam A, Dhathathreyan A and Madhusudhana Rao P 2003 Langmuir 195522

26. Hemakanthi G and Dhathathreyan A 1999 Langmuir 153317

27. Sing K S W, Everett D H, Haul R A W, Moscou L, Pietotti R A, Rouquerol J and Siemienieska T 1985 Pure Appl. Chem. 57603

28. Perkas N, Koltypin Y, Palchik O, Gedanken A and Chandrasekaran S 2001 Appl. Catal. A209 125

29. Srivastava D N, Perkas N, Seisenbaeva G A, Koltypin Y, Kessler V G and Gedanken A 2003 Ultrason. Sonochem. 101 